\title{
Estilo linguístico do gênero ata: objetividade e subjetividade
}

Linguistic style of the meeting minutes genre: objectivity and subjectivity

\author{
Juliana Hortelã ${ }^{1}$, Adélli Bortolon Bazza² \\ ${ }^{1}$ Universidade Estadual de Maringá (UEM), Brasil, Doutoranda em Letras (UEM), e-mail: juhortela@ gmail.com \\ ${ }^{2}$ Universidade Estadual de Maringá (UEM), Brasil, Doutora em Letras (UEM), professora adjunta no curso de Letras (Unespar), \\ e-mail: adellibazza@hotmail.com
}

\section{RESUMO}

Pautados em uma perspectiva discursiva de linha bakhtiniana, compreendemos a ata como uma manifestação social específica, fruto de condições concretas de produção e materializada em um texto com diversas peculiaridades estruturais e linguísticas. Nesse sentido, propomos, neste artigo, um estudo do estilo do gênero Ata. Para tanto, buscamos retomar a concepção de gênero do discurso a partir de Bakthin (1997), levantamos orientações técnicas a respeito da textualização das atas de acordo com o Manual de Redação da Presidência da República e opomos os dados levantados às ocorrências linguísticas verificáveis em um conjunto de atas institucionais selecionado. A análise dos dados indicou que, apesar dos manuais de redação oficial definirem a ata como um relato fiel das discussões e decisões de uma reunião, a objetividade anunciada para esse gênero apresenta brechas em que o secretário/redator atua, como a seleção de informações e de vocabulário a comporem o texto. Tais escolhas caracterizamse como pontos de ancoragem da subjetividade nas atas.

Palavras-chave: Discurso. Gênero ata. Secretariado.

\begin{abstract}
Based on a discursive perspective of Bakhtinian line, we understand the meeting minutes as a specific social manifestation, product of concrete conditions of production and materialized in a text with diverse structural and linguistic peculiarities. In that sense, we propose, in this paper, a study of the genre Minutes. To that end, we retrieved Bakhtin's (1997) conception of discourse genre and gathered technical guidance as to the minutes textualization according to the Writing Manual e of the Republic Presidency. We then contrasted the data gathered to the verifiable linguistic occurrences in a selected collection of institutional minutes. The data analysis indicated that, even though the official writing manuals define the minutes as a faithful report of the discussions and decisions of a meeting, the objectivity announced for this genre presents gaps in which the secretary/writer acts, as in the selection of information and vocabulary that compose the text. Such choices are defined as anchoring points to the subjectivity of the minutes.
\end{abstract}

Keywords: Discourse. Meeting minutes genre. Secretariat. 


\section{INTRODUÇÃO}

A ata é um tipo de documento de grande importância para as organizações. Utilizada tanto na administração pública quanto na privada, está presente no cotidiano do profissional de secretariado, pois é por meio deste gênero que se materializam os assuntos tratados em reuniões, assembleias, convenções etc.

De acordo com o Manual de redação da Presidência da República (BRASIL, 2018, p.16), "redação oficial é a maneira pela qual o Poder Público redige comunicações oficiais e atos normativos”. No Brasil, as empresas públicas devem seguir as normas desse manual para redigirem seus documentos. Já, para as empresas privadas, não há uma norma específica, apenas o Manual de redação oficial, que serve como orientação para a redação desses documentos do contexto organizacional.

A proposta deste artigo é estudar o gênero ata e tentar caracterizá-lo em suas nuances de estilo linguístico, pois identificamos a necessidade de conhecer o objeto antes de pensar em sua estratégia de ensino.

Tal inquietude surgiu quando, ao recorrer à bibliografia existente para o ensino dos gêneros específicos da área secretarial, encontramos nos conhecidos manuais de redação, concepções normativas ou estruturalistas da linguagem, as quais apresentam, por sua vez, modelos ideais de estruturas documentais e textuais. De tal forma, o Manual de redação oficial (BRASIL, 2018), diz que a redação oficial não é adversa à evolução da língua, porém, orienta que para exercer sua finalidade básica, que é a comunicação objetiva e clara, é necessário impor certos parâmetros ao uso que se faz da língua.

Dentre os gêneros característicos das organizações, podemos mencionar o memorando, as comunicações internas (Cis), porém, optamos por trabalhar com a Ata já que essa se trata de um documento bastante característico do contexto secretarial, uma vez que no decorrer da história da profissão a datilografia era algo intrínseco ao profissional. Obviamente, com o advento de tecnologias e outras mudanças ocorridas no contexto organizacional, como na vida em geral, a(s) forma(s) de materializar esse documento também se modificaram. No entanto, a redação da Ata é uma atribuição exclusiva do secretário. Ainda que seja redigida por uma pessoa com outra função na organização, chama-se de secretário aquele que a lavrou.

Revista Expectativa, Toledo/PR, v.20, n. 2, p. 51-66, abr./jun., 2021. 
Diante desse cenário, este ensaio abordará a concepção de gênero na perspectiva de Bakhtin (1997), o que nos faz tomar como parâmetro para diferenciar os gêneros a tríade: conteúdo temático, estilo linguístico e construção composicional. Além disso, essa visada implica levar em conta as condições de produção (finalidade, esfera, campo, autor, interlocutor) como fatores que atravessam e orientam todos os gêneros. Inicialmente, discutiremos sobre a concepção geral de gênero em Bakhtin. Feito isso, teorizaremos sobre o gênero ata e, por fim, apresentaremos o movimento analítico calcados nas discussões realizadas na seção teórica.

\section{REFERENCIAL TEÓRICO}

\subsection{OS GÊNEROS DO DISCURSO}

Nesta investigação objetivamos discutir a ata como um gênero discursivo, calcados na perspectiva de Bakhtin (1997). Esse teórico destaca que os gêneros do discurso são tipos relativamente estáveis de enunciados, já que a utilização da língua se dá por meio de enunciados (orais e escritos), concretos e únicos, que precisam de condições específicas para serem enunciados. Tais ocorrências acontecem nas mais variadas esferas da atividade humana, considerando que cada uma delas "comporta um repertório de gêneros do discurso que vai diferenciando-se e ampliando-se à medida que a própria esfera se desenvolve e fica mais complexa” (BAKHTIN, 1997, p. 279).

Diante disso, o autor ainda classifica os gêneros em dois grandes grupos: primários e secundários, os quais são entendidos, de uma forma geral, como simples e complexos (BAKHTIN, 1997). Ele também nos ensina que os gêneros primários são aqueles utilizados em situações cotidianas, já os classificados como secundários “aparecem em circunstâncias de uma comunicação cultural, mais complexa e relativamente mais evoluída, principalmente escrita: artística, científica, sociopolítica" (BAKHTIN, 1997, p. 282). Os gêneros primários e secundários se distinguem de acordo com a natureza do enunciado, ocorrendo sua inter-relação no e pelo processo histórico de formação dos gêneros secundários (BAKHTIN, 1997). No caso do gênero ata, tem-se um gênero secundário, posto que ele ocorre em uma situação de comunicação mais formal e ritualizada, além de incorporar gêneros primários, como o relato, reelaborando-o em sua tessitura.

Revista Expectativa, Toledo/PR, v.20, n. 2, p. 51-66, abr./jun., 2021. 
Sendo entendido que os gêneros se realizam na língua e a língua, por sua vez, se realiza nos gêneros por sujeitos individuais de forma heterogênea, vale ressaltar algumas esferas ou campos de circulação das práticas de linguagem, a saber: publicitária, escolar, cotidiana, jornalística, científica, artística, política. Tais esferas ou campos desenvolvem seus gêneros específicos. Entre uma imensidade de gêneros é possível citar: conto e crônica, na literatura; propaganda, panfleto e outdoor, na publicidade; sermão e oração, na religião; contrato, texto de lei, sentença, no campo jurídico; artigo de opinião e notícia, no jornalismo; resumo, resenha e artigo científico, no campo acadêmico-científico.

$\mathrm{Na}$ visada discursiva, entende-se que as atividades humanas determinam os conteúdos e os estilos de linguagem que vão se apresentar, nos gêneros, por meio de uma composição estrutural própria. Diante disso, Bakhtin (1997) estabelece a tríade passível de identificação que reconhece os gêneros discursivos, a saber: conteúdo temático, estilo e composição. Esses três elementos são indissolúveis ao enunciado, sendo, do mesmo modo, definidos pela especificidade de um determinado campo da comunicação. Assim, o enunciado precisa ter um conteúdo, no caso da ata, podemos pensar em uma reunião cujo conteúdo trate de uma fusão entre empresas, por exemplo. As escolhas lexicais que o sujeito redator vai materializar na ata constituem a estilística. Quanto ao campo em que este enunciado circula, podemos afirmar que se relaciona com organizações do campo econômico e/ou empresarial.

O conteúdo temático relaciona-se ao conteúdo que habitualmente é tratado como objeto de um determinado gênero. No caso da ata, são incontáveis conteúdos que podem abranger os mais variados tipos de assuntos. Podemos citar: deliberações, esclarecimentos, discussões, resoluções e demais ocorrências de uma reunião ou outro evento. É no conteúdo temático que observamos a forma com que se aborda o tema, podendo ser exaurido ou não.

Segundo Bakhtin (1997), a exaustão do conteúdo temático varia conforme as esferas da comunicação. Assim, o autor enfatiza que "teoricamente, o objeto é inesgotável, porém, quando se torna tema de um enunciado [...] recebe um acabamento relativo, [...] desde o início ele estará dentro dos limites de um intuito definido pelo autor" (BAKHTIN, 1997, p. 300). No caso da ata, a exaustão do conteúdo se dá de forma relativa, uma vez que, mesmo sendo, os detalhes e os discursos da reunião transcritos em sua totalidade, é sumarizado pelo sujeito que o redige. Ou seja, os assuntos, decisões são elencados por quem produz a ata, cabendo a ele a decisão de realizar os recortes dos depoimentos de acordo com o que julgar importante.

Revista Expectativa, Toledo/PR, v.20, n. 2, p. 51-66, abr./jun., 2021. 
Com relação às características da estrutura composicional, podemos destacar a presença de: a) cabeçalho: número da ata e o tipo de reunião; b) abertura: dia, mês, ano, hora, local, entidade, presidente, secretário, finalidade.

Quanto ao estilo, este reflete a individualidade dos sujeitos e revela a pluralidade dos estratos e dos aspectos intrínsecos à personalidade, as quais se apresentam em diferentes materializações da língua (BAKHTIN, 1997). Tal ocorrência é que faz a especificidade do estilo variar e torna-o gênero heterogêneo. Assim, nas palavras de Bakhtin:

\begin{abstract}
Cada esfera conhece seus gêneros, apropriados à sua especificidade, aos quais correspondem determinados estilos. [...] O estilo é indissociavelmente vinculado a unidades temáticas determinadas e, o que é particularmente importante, a unidades composicionais: tipo de estruturação e de conclusão de um todo, tipo de relação entre o locutor e os outros parceiros da comunicação verbal (relação com o ouvinte, ou com o leitor, com o interlocutor, com o discurso do outro, etc) (BAKHTIN, 1997, p. 284).
\end{abstract}

Contudo, vale ressaltar que, mesmo nos gêneros considerados mais engessados, há marcas de individualidades deixadas pelo autor. Além do fato de que o estilo também varia de acordo com os aspectos histórico-sociais e ideológicos. No caso da ata, podemos mencionar como características de estilo: formalidade, impessoalidade, clareza, ordem cronológica dos fatos, os indivíduos e suas decisões são citados. Ela é redigida em apenas um parágrafo, onde tudo é escrito seguidamente, com inutilização por barras dos espaços em branco nos finais de linhas.

Dentre as problemáticas de estilo mobilizadas por Bakhtin, destaca-se a variedade de possibilidade que o sistema linguístico nos oferece para materializar a linguagem, bem como, o estado de contínua mudança da língua (BAKHTIN, 1997). Tudo isso ocorre devido ao fato da linguagem se realizar em sujeitos vivos em constante transformação. Decorrente disso, podemos associar os diferentes tipos modalizações verbais, que por sua vez imprimem diferentes efeitos de sentido.

Ainda em relação ao estilo Bakhtin pondera (1997, p. 286), sobre "o problema geral dos princípios metodológicos aplicáveis ao estudo das correlações existentes entre o léxico e a gramática de um lado, e entre o léxico e a estilística do outro", pois, de acordo com o autor, gramática e léxico são distintos ao estilo e chegam a se oporem em algumas situações (BAKHTIN, 1997). O autor ainda salienta que há casos em que o estilo está totalmente relacionado à gramática e em outros se desliga totalmente. Por conseguinte, entendemos em 
Bakhtin (1997) que gramática e estilo podem estar unidos ou distanciados em qualquer ocorrência linguística concreta: quando observada pela ótica da língua, é um fato gramatical; quando observada pelo prisma do enunciado individual, é uma ocorrência de estilo.

Desse modo, a estilística varia de acordo com a individualidade dos sujeitos produtores dos enunciados, e no caso da ata, o estilo varia também de acordo com as instituições em que elas são produzidas. Assim, no material tomado para análise problematizaremos as categorias que as atas poderão trazer, como tempos e modos verbais, nomeação e retomada de objeto de discurso, a fim de mostrar a objetividade e a subjetividade na escolha lexical utilizada pelo sujeito redator, observando os posicionamentos e as posições sujeito assumidas.

Na próxima seção, passamos a desenvolver as especificidades do gênero ata de acordo com o Manual de redação da Presidência da República.

\subsection{O GÊNERO ATA}

Como mencionamos acima, a ata é um tipo de documento característico do contexto organizacional, utilizada tanto na administração pública quanto privada. Serve para registrar as informações ocorridas em assembleias, reuniões, encontros, conferências, dentre outros. É um meio de comunicação altamente formal, comprobatório que registra de forma resumida e fidedigno aos assuntos/deliberações de um encontro de pessoas, sendo redigida, geralmente, por um sujeito secretário.

Ignorando que a língua, bem como seu uso, é por natureza argumentativo, alguns manuais de redação oficial/empresarial preconizam a objetividade dos gêneros que circulam nessas esferas e não apontam suas características semânticos-argumentativas. De acordo com o Manual de redação da Presidência da República (BRASIL, 2018, p. 17), a redação oficial deve ser redigida de acordo com a norma padrão da língua portuguesa, deve ser clara, precisa, objetiva, coesa e coerente, formal e padronizada. O texto ainda complementa que tais atributos são decorrentes do art. 37 da Constituição, que diz: “A administração pública direta, indireta, de qualquer dos Poderes da União, dos Estados, dos Distrito Federal e dos Municípios obedecerá aos princípios de legalidade, impessoalidade, moralidade, publicidade e eficiência (...)". O documento (2018) ainda reitera que os princípios fundamentais de toda administração

Revista Expectativa, Toledo/PR, v.20, n. 2, p. 51-66, abr./jun., 2021. 
pública: publicidade, impessoalidade e eficiência, devem nortear a elaboração dos atos e das comunicações oficiais.

O Manual de redação da Presidência da República (2018, p. 17) tece sugestões acerca de elementos norteadores para redação de documentos oficiais. No elemento clareza recomenda que as palavras e expressões sejam simples e produzam sentido comum; que as frases sejam curtas, estruturadas e apresentem orações diretas; uniformidade do tempo verbal; que não sejam utilizados regionalismos e neologismos; que a pontuação seja adequada; que haja explicitação de siglas utilizadas; e se houver a necessidade de usar palavras em outro idioma marcar em itálico.

Quanto ao elemento precisão, o Manual (2018) orienta que haja articulação da linguagem comum ou técnica para melhor compreensão da ideia; que elas sejam expressas com as mesmas palavras, evitando o emprego de sinonímia estilística; e que as expressões utilizadas não causem ambiguidade. No que tange a objetividade, preconiza que devem ser evitados rodeios, redundâncias, sendo fundamental que o redator tenha ciência das ideias a serem tratadas. Quanto à concisão, indica a não utilização de palavras que tornem o texto redundante e repetitivo. Considera que se deve dispensar detalhes irrelevantes, evitando caracterizações e comentários supérfluos, adjetivos e advérbios inúteis, como, também subordinação excessiva.

No que diz respeito à coesão e coerência, o manual (BRASIL, 2018) afirma que a coesão e coerência de um texto entrelaçam as palavras, frases e parágrafos. Ainda, reitera que nesse quesito, estão marcados os mecanismos de referência, substituição, elipse e conjunções.

Em relação à impessoalidade, a orientação é que, devido a finalidade da redação oficial - a qual é agir em nome do serviço público atendendo ao interesse geral dos cidadãos - os assuntos e objetos devem ser estritamente impessoais. Sendo assim, a impessoalidade deve ser empregada quando: a) da ausência de impressões individuais de quem comunica; b) da impessoalidade de quem recebe a comunicação; c) do caráter impessoal do próprio assunto tratado.

$\mathrm{Na}$ seção seguinte, de acordo com o embasamento teórico acima fundamentado, procederemos à análise de características de estilo presentes em quatro atas oriundas do setor público. 


\section{PROCEDIMENTOS METODOLÓGICOS}

A produção da ciência se dá por meio de métodos pré-definidos os quais variam de acordo com o objeto e o campo de estudo em que se baseia determinada área. Neste caso, a pesquisa proposta possui abordagem qualitativa, na medida em que considera a relação de objetividade e subjetividade entre mundo e sujeito na interpretação dos fenômenos e atribuição de significados (GIL, 1996). Seu objetivo é descritivo analítico com procedimento técnico bibliográfico documental, a partir de referências do campo de estudos sobre gêneros textuais, buscou-se analisar em Atas, o estilo de textos que materializam esse gênero, de forma a problematizar aspectos linguísticos que evidenciem um efeito de objetividade ou de subjetividade na produção desses documentos. Para tanto, comungamos com a visão de Sobral; Soligo e Prado (2017, p. 178)

\footnotetext{
Ressaltamos que "subjetividade" não tem aqui o sentido de aparelho psíquico individual, de domínio pelas emoções em si, mas de situacionalidade, de posição enunciativa - social e histórica - de quem escreve. A objetividade fundada apenas no apagamento de marcas de subjetividade (por exemplo, dizer "verifica-se...") seria entendida assim como algo que busca criar um simulacro da ausência de um sujeito enunciador, um inútil ocultamento da autoria, pois esse agir supõe um autor que cria sua própria ausência e, assim agindo, deixa inevitavelmente marcas de seu agir, de sua presença criadora de ausência. A especular sobre isso dedicamos este nosso ensaio.
}

Diante disso, selecionamos um conjunto de quatro atas: 1- ata da $16^{\mathrm{a}}$ reunião extraordinária do conselho municipal dos direitos da criança e do adolescente de Maringá, realizada em sete de agosto de 2013; 2- Ata da assembleia geral extraordinária da Petrobrás, realizada em nove de agosto de 2019, 3- Ata da reunião extraordinária da Copel, realizada em oito de agosto de 2019; 4- Ata de reunião ordinária da Copel, realizada em quatro de setembro de 2019. O recorte recaiu sobre atas de órgãos e empresas públicas que estão disponíveis on line, dada a dificuldade em se ter acesso a atas de empresas privadas. Para tanto, foi pesquisado pelo termo 'ata' no buscador google e foram selecionados os primeiros quatro resultados de atas publicadas na íntegra e que atendessem ao critério de sua origem. Em seguida, elas foram lidas de modo a levantar elementos linguísticos recorrentes e significativos para a constituição de seu estilo. 


\section{ANÁLISE DOS DADOS E INTERPRETAÇÃO DE RESULTADOS}

Para tratar do par objetividade/subjetividade amparamo-nos em reflexões de linguístas como Benveniste (1995) a respeito dos espaços para manifestação do sujeito dentro de um sistema linguístico dado. De acordo com o autor (1995, p. 286), “a 'subjetividade' de que tratamos aqui é a capacidade do locutor para se propor como ‘sujeito'. [...] É ‘ego' que diz ego. Encontramos aí o fundamento da 'subjetividade' que se determina pelo status linguístico da 'pessoa"',

A subjetividade na linguagem poderia, portanto, ser localizada em um conjunto de marcas linguísticas, a saber: pronomes pessoais; temporalidade; modalizações em relação aos verbos; uso de performativos. Quanto aos pronomes "eu" e "tu" seriam sujeitos da enunciação enquanto "ele" a pessoa/objeto de que se fala. Dessa maneira, a terceira pessoa assume uma função mais objetiva dentro dos textos que a primeira e a segunda.

Ainda de acordo com Benveniste (1995), a noção de tempo tem como marco o sujeito e o momento em que ele enuncia. Contudo, existe a possibilidade de não coincidência entre os tempos cronológicos e linguísticos. Um exemplo disso seria o uso do tempo presente para descrição de fatos históricos, como: 'Cabral chega ao Brasil em 21 de abril de 1500'. Outro recurso para marcação da subjetividade consiste na seleção e modalização dos verbos, por exemplo: em 'o tempo vai mudar' tem-se um dado objetivo, já em 'sinto que o tempo vai mudar' e 'creio que o tempo vai mudar', adiciona-se um traço subjetivo à primeira informação. A presença dos performativos na língua também desvela a subjetividade, pois, se dizer é fazer, quem faz é o sujeito. Como podemos observar nesse exemplo: Dizer ‘eu juro’ implica o próprio ato de jurar e não apenas a descrição de algo.

Diante de inúmeros recursos que evidenciam a presença da subjetividade, o trabalho do secretário consistiria em evitá-los, lançando mão de escolhas lexicais que criem o efeito de objetividade. Entre os diversos aspectos da língua que favorecem efeito de objetividade e geram o foco no assunto tratado, pode-se citar o sujeito na terceira pessoa do singular, por exemplo: 'iniciou-se a reunião'. Contribui para esse mesmo efeito o uso da voz passiva: 'o empréstimo foi aprovado', assim, como preconiza o Manual de redação da Presidência da República (2018) no que tange a impessoalidade. Desse modo, evita-se discutir as pessoas que estavam na reunião, suas manifestações particulares e se avança apenas para a decisão, focalizada na

Revista Expectativa, Toledo/PR, v.20, n. 2, p. 51-66, abr./jun., 2021. 
posição de sujeito da oração passiva. A exatidão de datas, quantidades e valores, ao longo do texto também contribui para esse feito de objetividade

Por outro lado, é possível encontrar, dentro desse gênero que se pretende tão objetivo e fiel aos fatos, índices linguísticos da subjetividade do secretário. O primeiro deles é o uso da primeira pessoa do singular, pois é padrão que a ata seja encerrada com a fórmula 'e eu, fulano, lavrei a presente ata". Assim, por mais que todo o relato seja apresentado como impessoal e objetivo, o encerramento da ata relembra o leitor de que ela é o fruto da leitura que uma pessoa fez dos fatos ocorridos em uma reunião. Outro recurso que demonstra um certo posicionamento do autor tem a ver com a seleção do léxico, sejam os verbos (sugeriu, questionou, indicou, ordenou) seja das expressões adverbiais (logo, conforme a concordância dos presentes, para encerrar). Se tomamos o gênero como o lugar da textualização de um discurso que é, por natureza, dialógico, entenderemos que ele nunca será neutro.

$\mathrm{Na}$ Ata 1, encontramos diversos recursos de estilo que indicam a busca pelo efeito de objetividade no gênero, a primeira delas é a presença de dados exatos como dia, hora e local:

Aos sete dias do mês de agosto de dois mil e treze, no Auditório Hélio Moreira, Paço Municipal de Maringá, às oito horas e trinta minutos, deu-se início a décima sexta Reunião Extraordinária do Conselho Municipal dos Direitos da Criança e do Adolescente de Maringá - Gestão dois mil onze a dois mil e treze. (Ata 1)

Outro efeito elemento que favorece essa impessoalidade e objetividade no gênero é o uso da voz passiva, para dar foco ao assunto e não às pessoas envolvidas na reunião.

A reunião foi presidida pelo Presidente Ailton José Morelli e participaram os Conselheiros nominados com as respectivas assinaturas em lista de presença que integra esta Ata.

Além disso, a busca por nomear as pessoas a partir de seus cargos ou funções dentro da instituição, cria um efeito de distanciamento e, consequentemente, de neutralidade do secretário em relação ao citado:

A conselheira Patrícia solicitou à plenária confirmação se os conselheiros possuem alguma objeção em analisar o documento com quórum mínimo, uma vez que já foi adiada a reunião por várias vezes por não haver quórum específico.

A assessora Eloacy informou ainda que foram agendados novos dias para que continuassem as visitas para recadastro das entidades e pede a cooperação dos demais conselheiros para que auxiliem a comissão de monitoramento e não tenha atraso nos documentos de recadastro.

Revista Expectativa, Toledo/PR, v.20, n. 2, p. 51-66, abr./jun., 2021. 
Em contraste com o efeito de objetividade alcançado com os recursos anteriores, há elementos linguísticos de indicam a presença da subjetividade na ata. Entre eles, pode-se destacar certo lapso do secretário ao relatar:

O presidente informou que estamos aprovando o regimento interno do conselho, documento este que norteia as especificidades internas de ação do CMDCA e que não podemos agir nos regimentos internos de outros órgãos.

Provavelmente, durante a reunião, o uso da primeira pessoa do plural foi a escolha do presidente ao falar, contudo, essa primeira pessoa, ao fazer parte do texto de relato da ata quebra o efeito de relato e de distanciamento que vinha sendo construído, em termos de estilo, até o momento. Para manter o efeito objetivo, seria esperada a continuidade do uso da voz passiva: 'o regimento interno está sendo aprovado', por exemplo.

Em relação, os trechos já apresentados:

A conselheira Patrícia solicitou à plenária confirmação se os conselheiros possuem alguma objeção em analisar o documento com quórum mínimo, uma vez que já foi adiada a reunião por várias vezes por não haver quórum específico.

A assessora Eloacy informou ainda que foram agendados novos dias para que continuassem as visitas para recadastro das entidades e pede a cooperação dos demais conselheiros para que auxiliem a comissão de monitoramento e não tenha atraso nos documentos de recadastro.

Observa-se que, em meio às marcas de objetividade, vazam elementos imprecisos o texto. Diante da expressão 'várias vezes', o leitor não tem ideia de quantas sejam, da mesma forma que não sabe exato quantas pessoas precisam estar presentes para formar um 'quórum mínimo’ e pode ficar se perguntando quantos havia e quantos faltam naquela reunião. Ao relatar que foram agendados 'novos dias', também não é possível saber ao certo quantos e quais serão esses dias. Isso ocorre de forma contrária ao que orienta o Manual de Redação da Presidência da República (2018), em relação à clareza e precisão das redações.

A escolha léxica, também constitui um índice da subjetividade na produção do gênero ata:

A conselheira Solange Botion solicitou também que fosse novamente analisado esse assunto, pois não se sentiu contemplada com a decisão anterior da plenária. $O$ presidente informou que não há nada especificado na lei municipal que mude a recondução de conselheiros. A conselheira Patrícia ressaltou a necessidade de ser especificado no regimento se o conselho aceita ou não a recondução dos conselheiros.

Revista Expectativa, Toledo/PR, v.20, n. 2, p. 51-66, abr./jun., 2021. 
Iniciou-se uma discussão sobre o assunto e quanto tempo ele pode ser representante no conselho, sendo governamental ou não.

Solicitou pode ser a síntese de a pessoa dizendo: ‘eu solicito’, ‘eu peço’, ‘eu quero', ‘eu gostaria' ou 'eu exijo'. Ao ler que a pessoa não se sentiu contemplada não é possível ter certeza se a regra não abarca o caso dela ou se a desfavorece. Da mesma forma, ao relatar que houve uma discussão, o secretário lida com a polissemia do termo que pode indicar tanto um evento amistoso como não. O leitor não tem como ter acesso a essa informação pela ausência de detalhes mais específicos sobre como as coisas objetivamente aconteceram naquela reunião.

Todos esses indícios da subjetividade do secretário ao redigir a ata se materializam na forma final e recorrente com que se encerra o texto, posto que ali, a pessoa se marca:

Às 11h00min, o Presidente Aílton agradeceu a participação de todos, encerrando a reunião. Eu, Rita Aparecida Rueda, lavrei a presente ata que após lida e aprovada, vai por mim assinada e pelo Presidente e os Conselheiros em lista própria.

A ata 2 consiste no relato das decisões tomadas em uma reunião da Petrobrás. Ela apresenta uma estrutura de composição diferenciada: está redigida em tópicos e parágrafos, com espaçamentos entre eles. Tal característica necessitou ser aprovada e justificada, o que demonstra que a redação da ata em parágrafo de um bloco é bastante comum e tomada como regra.

O estilo dessa ata é bastante definido em função das peculiaridades de suas condições de produção: as informações a serem discutidas são apresentadas de antemão aos acionistas que deliberam antes mesmo de a reunião acontecer. No dia, tanto a reunião quanto o relato dela são bastante protocolares. Isso favorece que prevaleçam aspectos de objetividade na sua redação. Entre eles é possível destacar: a apresentação de dados como local, data, hora e nome dos presentes, bem como as tabelas de votos dos presentes.

Assembleia realizada no dia 09 de agosto de 2019, às 15 horas, na sede social da Companhia, na Avenida República do Chile n. 65, Centro, Rio de Janeiro, RJ.

Estavam presente na Assembleia Geral Extraordinária acionistas representando percentual correspondente a 89,32\% das ações ordinárias que compõem o capital social, conforme atestam os registros e as assinaturas no Livro de Presença de Acionistas, convocados através do Edital de Convocação publicado nas edições dos dias 9, 10, 11 e 12 de julho de 2019 do periódico Diário Oficial do Estado do Rio de Janeiro e dos dias 9, 10 e 11 do periódico Valor Econômico.

Revista Expectativa, Toledo/PR, v.20, n. 2, p. 51-66, abr./jun., 2021. 
A ata 3 refere-se a uma reunião extraordinária da Copel e é bastante sucinta. Trata-se, basicamente da informação de que a reunião foi adiada e remarcada para o dia em que haverá informações a serem apreciadas. Provavelmente, devido à gestão da empresa, que tem reuniões ordinárias previamente estabelecidas, não foi possível adiar a reunião informalmente, então fezse uma ata para registrar isso.

Ela apresenta estrutura em tópicos e, apesar de pouco apresentar em termos de discussões (dado o fato de que a reunião não aconteceu realmente) constitui-se inicialmente a partir de elementos de estilo próprios da ata ao iniciar com aspectos objetivos de local, data, nomeação de membros.

1. LOCAL: Rua Coronel Dulcídio ${ }^{\circ}$ 800, Curitiba - PR. 2. DATA: 08.08 .2019 - 16 horas. 3. MESA DIRIGENTE: MARCEL MARTINS MALCZEWSKI - Presidente; DANIEL PIMENTEL SLAVIERO - Secretário Executivo; e DENISE TEIXEIRA GOMES - Secretária da Reunião.

Reforça o efeito de objetividade desta ata o fato de que nem o encerramento apresenta a estrutura recorrente em que o secretário nomeia-se como eu. Ao contrário, os nomes das pessoas que assinam a ata são apenas listados, juntamente com a função de cada um.

A ata 4 tem uma apresentação padrão, feita em bloco único e, assim como as anteriores, está permeada de informações objetivas sobre local, data, membros presentes.

No dia quatro de setembro de dois mil e dezenove, às oito horas e trinta minutos, na sede da Companhia, na Rua Coronel Dulcídio, 800 - $10^{\circ}$ andar, Curitiba - PR, reuniram-se os membros do Conselho de Administração - CAD que ao final assinam.

A apresentação de valores exatos do quanto cada sócio investirá contribui para o feito de objetividade do texto:

\footnotetext{
Adicionalmente, o Sr. Bertol reafirmou a necessidade da continuidade de realização de Adiantamento para Futuro Aumento de Capital - AFAC, pelas sócias, no valor total de $\mathbf{R} \$ \mathbf{4 5 . 2 8 1 . 5 7 2 , 0 0}$, sendo que cada sócia irá contribuir de acordo com sua participação. Informou que ao Grupo Copel corresponde o valor de $\mathbf{R} \$ \mathbf{3 6 . 2 2 5 . 2 5 7 , 6 0}$, sendo R\$9.056.314,40 a parte correspondente à sócia Copel (Holding) e $\mathrm{R} \$ 27.168 .943,20$ a parte correspondente à sócia Copel Geração e Transmissão S.A. Copel GeT, dos quais já foram realizados $\mathrm{R} \$ 21.093 .725,81$, sendo $\mathbf{R} \$ \mathbf{1 5 . 8 2 0 . 2 9 4 , 3 6}$ referentes à participação da Copel GeT e R\$5.273.431,45 à participação da Copel (Holding), restando ainda $\mathbf{R} \$ \mathbf{1 5 . 1 3 1 . 5 3 1 , 7 9 .}$
}

Outro aspecto de estilo que confere objetividade a esta ata é o predomínio do uso da voz ativa, relatando cada um dos membros e o que ele fez:

Revista Expectativa, Toledo/PR, v.20, n. 2, p. 51-66, abr./jun., 2021. 
... o Sr. Adriano Rudek de Moura, Diretor de Finanças e de Relações com Investidores, acompanhado de sua equipe, apresentou os destaques sobre o cenário financeiro da Copel e informações sobre receita líquida e EBITDA do consolidado do $3^{\circ}$ trimestre de 2019 (realizado até julho de 2019)...

Em vários momentos, há uma personificação do Conselho, para indicar quando um assunto é aprovado ou não, mas evita-se a voz passiva.

o Conselho de Administração recebeu informações atualizadas e conheceu os próximos passos para o trabalho de desenvolvimento do Planejamento Estratégico 2020-2024, por meio do relato do Sr. André Luís de Castro David, Superintendente da Coordenação de Planejamento e Gestão do Desempenho Empresarial

Entre os aspectos que não favorecem a objetividade é possível citar a falta ou vaguidão de algumas informações. Por exemplo: é relatado que alguém apresentou o cenário financeiro da empresa, mas os dados que comprovam isso e as ponderações são omitidos, o que relacionado ao contexto de produção e circulação desse gênero, pode indicar uma forma de preservação da empresa. Contudo, para efeitos legais e de retomada de questões futuras, tais informações pouco ajudam. Em certo momento, afirma-se: “Após análise da referida carta”, mas a forma como isso foi feito não está registrada. O leitor pode ficar se questionando se a análise foi individual, coletiva, se alguém falou e os demais apenas concordaram, mas o texto da ata não esclarece. $\mathrm{O}$ mesmo acontece em:

Os Conselheiros de Administração, após tomar conhecimento do assunto, debateram o tema e registraram suas considerações.

Não se sabe quais considerações são essas e onde elas foram registradas. Caso seja interesse da empresa retomar essas informações, ficará difícil. Depois de uma lista de informações técnicas que foram apresentadas na reunião e não relatadas na ata, o texto registra que:

Os Conselheiros de Administração apreciaram informações sobre a Fundação Copel e os Planos de Previdência e de Saúde patrocinados pela Copel e discutiram a matéria. Foi registrado que os Membros do Comitê de Auditoria Estatutário - CAE, conforme deliberado em sua $199^{a}$ Reunião, de 03.09.2019, assistiram a apresentação em referência juntamente com este Conselho e debateram o tema.

Assim como nos exemplos anteriores, não é possível saber quais discussões seriam essas. Essa imprecisão de informações, por um lado, preserva a empresa, posto que, sendo 
estatal, tem suas atas tornadas públicas. Por outro lado, não se alinham ao efeito de objetividade preconizado pelo Manual de Redação da Presidência comum à grande maioria das atas.

As atas analisadas demonstram que, apesar de descrito como um gênero em que predomina a objetividade, constitui-se com um número significativo de elementos de subjetividade. Se, do lado do primeiro efeito tem-se o uso de: sujeito na terceira pessoa; voz passiva; dados exatos; do lado do segundo efeito, observa-se a presença de: uso da primeira pessoa; seleção parcial do léxico; relatos lacônicos.

\section{CONSIDERAÇÕES FINAIS}

Nesse trabalho, propusemo-nos empreender um estudo do estilo no gênero Ata a partir dos pressupostos enunciativos sobre gêneros do discurso (1997). Para isso, levantamos orientações técnicas a respeito da textualização das atas de acordo com o Manual de Redação da Presidência da República e opusemos os dados levantados às ocorrências linguísticas verificáveis em um conjunto de 4 (quatro) atas de instituições públicas.

A análise dos dados indicou que, apesar do Manual de redação da Presidência preconizar a objetividade deste gênero, há diversos pontos de subjetividade do secretário/redator, indo ao encontro de diversos pontos de subjetividade como a polifonia. Assim, mesmo sendo a ata definida como um relato fiel das discussões e decisões de uma reunião, a objetividade anunciada para esse gênero apresenta brechas em que o secretário/redator atua, como a seleção de informações de vocabulário a comporem o texto. Portanto, tais escolhas caracterizam-se como pontos de ancoragem da subjetividade nas atas.

Vale ressaltar que esse trabalho ainda permite analisar outras questões, como a abordagem de outros elementos linguísticos que contribuem na objetividade e subjetividade, tal qual as formas de modalização, as vozes ativa ou passiva e até mesmo um aprofundamento dos estudos dos gêneros ressaltando as questões valorativas, axiológicas e seus desdobramentos.

\section{REFERÊNCIAS}

BAKHTIN, Mikhail. Estética da Criação Verbal. Tradução. M.E.G. Gomes. 2. ed. São Paulo: Martins Fontes, 1997.

BENVENISTE, Émile. Problemas de Linguística Geral I. 4. ed. Campinas, SP: Pontes, 1995

Revista Expectativa, Toledo/PR, v.20, n. 2, p. 51-66, abr./jun., 2021. 
BRASIL, Presidência da República Casa Civil. Manual de redação da Presidência da República/Casa Civil, Subchefia de Assuntos Jurídicos. Coordenação de Gilmar Ferreira Mendes, Nestor José Forster júnior [et al.]. 3. ed., rev., atual. e ampl. - Brasília: Presidência da República, 2018. Disponível em

http://www4.planalto.gov.br/centrodeestudos/assuntos/manual-de-redacao-da-presidencia-darepublica/manual-de-redacao.pdf. Acesso em: 30 set. 2019.

COPEL. Ata da centésima octogésima sétima reunião extraordinária do Conselho de Administração. Disponível em: https://ri.copel.com/ptb/reunioes-do-conselho-deadministracao-e-fiscal/2019. Acesso em: 10 fev. 2020.

COPEL. Ata da centésima nonagésima quarta reunião ordinária do Conselho de Administração. Disponível em: https://ri.copel.com/ptb/reunioes-do-conselho-deadministracao-e-fiscal/2019. Acesso em: 10 fev. 2020.

GIL, Antônio C. Métodos e técnicas de pesquisa social. 5. ed. São Paulo: Atlas, 2006.

LIMA, Sandra Mara Moraes. Concepção bakhtiniana de linguagem e de gênero discursivo: uma análise das orientações curriculares de língua portuguesa para o ensino médio.

Entretextos, Londrina, v.12, n.1, p.164-177, jan./jun. 2012.

MARINGÁ, Conselho Municipal dos direitos da criança e do adolescente. Ata da $\mathbf{1 6}^{\mathbf{a}}$ reunião extraordinária do Conselho Municipal dos Direitos da Criança e do Adolescente - CMDCA - GESTÃ̃ 2011 -2013. Disponível em:

http://www2.maringa.pr.gov.br/sistema/arquivos/c666e33b0ee9.pdf Acesso em: 10 fev. 2020.

NASCIMENTO, Erivaldo Pereira do. Gêneros do universo oficial/empresarial: para além dos manuais de redação. Revista de Gestão e Secretariado, São Paulo, v.1, n.2, p.123-142, jul./dez., 2010.

NASCIMENTO, Erivaldo Pereira do. A polifonia de locutores no gênero ata: estratégia semântico-argumentativa. Revista do Programa de Pós-Graduação em Letras da Universidade de Passo Fundo, Passo Fundo, v.8, n.2, p.112-130, jul./dez., 2012

PETROBRAS. Ata da Assembleia Geral Extraordinária da Petróleo Brasileiro S/A PETROBRÁS, realizada em 9 de agosto de 2019. Disponível em:

https://www.investidorpetrobras.com.br/ptb/15425/9512_705994..pdf. Acesso em Acesso em: 10 fev. 2020.

POSSENTI, Sírio. Discurso, estilo e subjetividade. São Paulo: Martins Fontes, 1988.

SOBRAL, A.; SOLIGO, R.; PRADO, G. V. T. A subjetividade autoral em textos acadêmicos: algumas considerações. Nonada: Letras em Revista, n. 28, v. 1, p. 174-193, maio, 2017.

Revista Expectativa, Toledo/PR, v.20, n. 2, p. 51-66, abr./jun., 2021. 